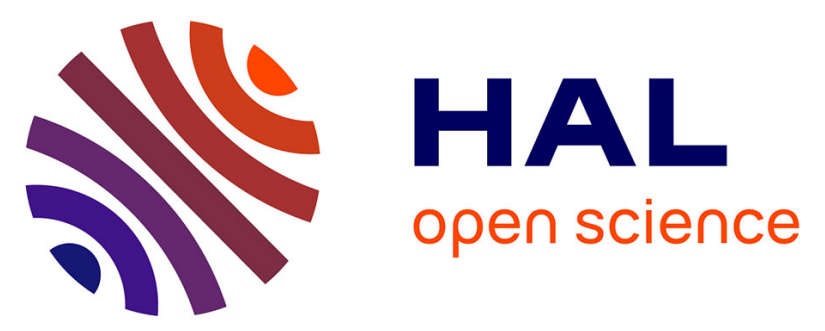

\title{
Miniaturization of an extraction protocol for the monitoring of pesticides and polar transformation products in biotic matrices
}

Vincent Dufour, Laure Wiest, Sylvain Slaby, François Le Cor, Lucile Auger, Olivier Cardoso, Laurence Curtet, Laure Pasquini, Xavier Dauchy, Emmanuelle Vulliet, et al.

\section{To cite this version:}

Vincent Dufour, Laure Wiest, Sylvain Slaby, François Le Cor, Lucile Auger, et al.. Miniaturization of an extraction protocol for the monitoring of pesticides and polar transformation products in biotic matrices. Chemosphere, 2021, 284, pp.131292. 10.1016/j.chemosphere.2021.131292 . hal-03364505

\author{
HAL Id: hal-03364505 \\ https://hal.science/hal-03364505
}

Submitted on 13 Oct 2021

HAL is a multi-disciplinary open access archive for the deposit and dissemination of scientific research documents, whether they are published or not. The documents may come from teaching and research institutions in France or abroad, or from public or private research centers.
L'archive ouverte pluridisciplinaire HAL, est destinée au dépôt et à la diffusion de documents scientifiques de niveau recherche, publiés ou non, émanant des établissements d'enseignement et de recherche français ou étrangers, des laboratoires publics ou privés. 


\title{
Miniaturization of an extraction protocol for the monitoring of pesticides and polar transformation products in biotic matrices
}

\author{
Vincent Dufour ${ }^{\text {ab }}$, Laure Wiest ${ }^{b}$, Sylvain Slaby ${ }^{\text {a, }}$ François Le Cor ${ }^{\text {ac }}$, Lucile Auger ${ }^{\text {ad }}$, Olivier \\ Cardoso ${ }^{\mathrm{e}}$, Laurence Curtet ${ }^{\mathrm{d}}$, Laure Pasquini ${ }^{\mathrm{c}}$, Xavier Dauchy ${ }^{\mathrm{c}}$, Emmanuelle Vulliet ${ }^{\mathrm{b}}$, Damien \\ Banas $^{\text {a }}$ \\ ${ }^{a}$ Université de Lorraine, INRAE, URAFPA, F-54000, Nancy, France \\ ${ }^{\mathrm{b}}$ Univ Lyon, CNRS, Université Claude Bernard Lyon 1, Institut des Sciences Analytiques, UMR \\ 5280, 5 rue de la Doua, F-69100, Villeurbanne, France \\ c LHN, Laboratoire d'Hydrologie de Nancy, ANSES, 40 rue Lionnois, F-54000, Nancy, France \\ d Office Français de la Biodiversité, Montfort, F-01330, Birieux, France \\ e Office Français de la Biodiversité, 9 Avenue Buffon, F-45071, Orléans, France
}

\section{Introduction}

2 Pesticides, or plant protection products (PPPs), are widely used across the world to increase

3 agricultural yields. As only some of the applied dose reaches target organisms, a significant amount

4 of active substances ends up in the environment, depending on the PPPs, environmental conditions,

5 and agricultural practices (Gaillard et al. 2016b). Aquatic ecosystems play the role of final

6 receptacles for organic micropollutants, with concentration levels ranging from ultra-traces to $\mu \mathrm{g} . \mathrm{L}^{-1}$

7 (Gaillard et al. 2016a; Nowell et al. 2018). Gaillard et al. (2016a) estimated PPP concentrations of up to $20 \mu \mathrm{g} . \mathrm{L}^{-1}$ in streams located in headwater agricultural catchments. Moreover, PPPs can affect the

9 health of wild organisms such as macroinvertebrates (MIs) (Macchi et al. 2018), amphibians (Slaby

10 et al. 2019), fish (Clasen et al. 2018), and birds (Stanton et al. 2018; Brain and Anderson 2019), and

11 biodiversity in general (McLaughlin and Mineau 1995; Geiger et al. 2010). Bioaccumulation and

12 bioamplification along the trophic chain are of particular concern as they may result in increased

13 contamination levels in top predators (Konwick et al. 2006; Rostron 2010). To overcome these

14 phenomena, more polar PPPs have been synthesized. However, they can reach aquatic ecosystems

15 and contaminate wild organisms even more easily because of their intrinsic mobility. In addition, 
16 PPPs can undergo biotic and abiotic processes in the environment that lead to the generation of

17 transformation products (TPs) being usually more stable, polar, and mobile (Reemtsma et al. 2016),

18 and sometimes having more effects on organisms (Sinclair and Boxall 2003; Tousova et al. 2017)

19 than their parent compounds. There is a current gap in knowledge on these polar mobile organic

20 chemicals (PMOCs) since, compared to historic PPPs, their nature and dynamics in the environment

21 are poorly known (Reemtsma et al. 2016) despite their potential toxicity at low concentrations.

22 Filling this gap would require the use of specific analytical tools and method such as ion

23 chromatography, that are usually not compatible with multi-residues analysis of medium to non-

24 polar compounds.

25 The QuEChERS (quick, easy, cheap, effective, rugged, and safe) method (Anastassiades et al. 2003)

26 is one of the most universal extraction approach for multi-residue analysis of pesticides, including

27 polar pesticides. It usually ensures good extraction rates (ERs) for a large number of substances

28 (Knoll et al. 2020). This method was successfully applied to solid matrices with different levels of

29 complexity such as fruit and vegetables (Lehotay et al. 2010; Koesukwiwat et al. 2010), meat and

30 fish (Lazartigues et al. 2011; Lichtmannegger et al. 2015; Oliveira et al. 2018), or food from animal

31 origin (Giroud et al. 2013; Golge et al. 2018; Song et al. 2019). However, owing to their nature, more

32 polar substances such as TPs present other analytical challenges. Indeed, they are more soluble in the

33 aqueous phase than in acetonitrile, even if the latter is saturated with buffer, resulting in low or no

34 recoveries. (Dufour et al. 2020).

35 Another disadvantage of most current extraction methods is the use of high sample masses, usually

36 greater than $1 \mathrm{~g}$, that can be very difficult to obtain for many environmental matrices. This hinders

37 the study of PPP transfers in food webs for two reasons: (1) it may not be possible to collect enough

38 biomass to analyze pesticides in smaller organisms such as insects or small fish (Knoll et al. 2020);

39 or (2) individuals must be pooled, which may lead to less accurate results (Roche et al. 2009). This is

40 typically the case for MIs (e.g., insect or crustacean larvae), which have small individual masses but 
41 play a key role in trophic chains by ingesting plant matter and then being consumed by predators

42 (Four et al. 2019). Developing analytical methods to quantify the contamination of this trophic level

43 is a major challenge for modeling PPP transfers in ecosystems. Moreover, it may also represent an

44 interesting tool for the monitoring of marine mammals, reptiles and apex predators from a biopsy,

45 avoiding euthanasia or invasive surgery to obtain sufficient material for analysis, which is an actual

46 need concerning the assessment of micropollutants in marine wildlife (Sanganyado et al., 2020).

47 Providing a robust, reliable, and sensitive analytical method based on low matrix masses could

48 increase the number of studies in that research field and benefit the understanding of the global

49 dynamics of organic micropollutants in the environment. In this context, the aim of this work was to

50 study the effect of the miniaturization of a previously developed extraction protocol (Dufour et al.,

51 2020) on analytical performance and to test its applicability on two matrices: fish and MIs. As

52 masses of MI samples are very low, the effect of miniaturization was first investigated on fish, and

53 then applied and validated on MIs. Special attention was paid to the validation phase in order to

54 guarantee the reliability and accuracy of the method as it is well known that decreasing the reduction

55 of the sample mass increases the variability of the measurement (Han et al., 2018; Lehotay et al.,

56 2018).

\section{Materials and methods}

60 Ultrapure water (Fisher Chemical, Geel, BE), acetonitrile (ACN) (Honeywell, Seelze, DE), and

61 heptane (Merck, Darmstadt, DE) were of LC-MS quality. Magnesium sulfate $\left(\mathrm{MgSO}_{4}\right)$ was

62 purchased from Sigma-Aldrich (Saint Louis, USA). Formic acid (FA) and ammonium sulfate were

63 purchased from Biosolve-chemicals (Dieuze, FR). Fifty-milliliter polypropylene metal-free

64 centrifuge tubes were purchased from VWR (Fontenay-sous-Bois, FR) and $2 \mathrm{~mL}$ polypropylene

65 safe-lock centrifuge tubes were obtained from Eppendorf (Montesson, FR). Forty-one analytical 
standards and 15 isotopically labeled standards (Table S1) were purchased from A2S (Martignas-surJalle, FR), Honeywell (Seelze, DE), HPC standards (Cunnersdorf, DE), LGC group (Teddington, UK), Sigma-Aldrich (Saint-Louis, USA), and TCI Europe (Anvers, BE). All were of high purity $(>96 \%)$ with most $>99 \%$. Individual solutions made in acetonitrile $\left(100 \mathrm{mg} . \mathrm{L}^{-1}\right)$ were stored at $18^{\circ} \mathrm{C}$. They were mixed to obtain a $5 \mu \mathrm{g} . \mathrm{L}^{-1}$ solution used to develop and validate the extraction protocol. Mix solutions were regularly characterized to check their stability over time and data were compiled in a control chart. Stored at $-18^{\circ} \mathrm{C}$, they were stable for at least 6 months.

Young tench (Tinca tinca) $(\mathrm{n}=13)$ were provided by the experimental platform of aquaculture (URAFPA, University of Lorraine) and were used as a blank reference matrix for fish. The MI reference matrix consisted in chironomid larvae reared under laboratory conditions, kindly provided by INRAE (ECOTOX team, Centre Lyon-Villeurbanne, FR).

For this purpose, fish and MIs were both sampled in November 2018 in two fishponds of the Dombes region (FR), over 2 distinct days. Those fishponds have watershed strongly influenced by conventional farming with the presence of either grassland or maize, wheat or rape crops. Fish and MI are expected to be exposed to diverse pesticides at important levels, and more especially herbicides like metazachlor and metolachlor, which are often applied to this type of crop, as well as to their TPs. Three fish species were selected for their representativeness of the local production: carp (Cyprinus carpio, $\mathrm{n}=6$ ), roach (Rutilus rutilus, $\mathrm{n}=6$ ), and rudd (Scardinius erythrophthalmus, $\mathrm{n}=5)$. On average $( \pm$ SEM), they weighed $247.5 \pm 11.2,58.3 \pm 3.5$, and $37.6 \pm 12.2 \mathrm{~g}$ wet weight (ww), respectively. Concerning MIs, organisms were pooled to constitute 19 samples according to taxonomic classification. They were sorted into Anisoptera $(n=2)$, Chironomidae $(n=5)$, Corixidae $(\mathrm{n}=5)$, Daphniidae $(\mathrm{n}=2)$, Dystiscidae $(\mathrm{n}=1)$, and Physidae $(\mathrm{n}=4)$ groups. All blank reference matrices and samples (whole organisms) were frozen at $-20^{\circ} \mathrm{C}$ in aluminum tray. Then, they were 
91 freeze-dried (Reacti-Vap, PIERCE, Bellafonte, USA), ground, and stored at room temperature until

92 extraction.

\subsection{Initial protocol}

95 The initial protocol (IP), based on a previous work by Dufour et al. (2020) and designed for the 96 analysis of pesticides and their degradation products in high-mass environmental samples (e.g., 97 eggs), is illustrated in Fig. 1. Briefly, $500 \mathrm{mg}$ of sample was placed in a $50 \mathrm{~mL}$ centrifuge tube and 98 spiked with $50 \mu \mathrm{L}$ of a $500 \mu \mathrm{g} . \mathrm{L}^{-1}$ mix solution containing all standards to constitute artificial 99 samples. The solvent of the solution was evaporated under gentle nitrogen flux for 10 min and the 100 spiked matrix was mixed with $5 \mathrm{~mL}$ of LC-MS water at $16 \mathrm{~Hz}$ for $10 \mathrm{~min}$ (SamplePrep 2010 101 Geno/Grinder from SPEX, Costa Mesa, USA). Then, $5 \mathrm{~mL}$ of heptane and $10 \mathrm{~mL}$ of ACN (+ $1020.2 \%$ FA) were added and the whole sample was mixed again at $16 \mathrm{~Hz}$ for 10 min before 103 centrifugation at 9,500 RCF (Relative Centrifugal Force) at $20^{\circ} \mathrm{C}$ for $5 \mathrm{~min}$. Six milliliters of the 104 lower layer (ACN/water mix) was dehydrated over $2.5 \mathrm{~g}$ of $\mathrm{MgSO}_{4}$ in a $50 \mathrm{~mL}$ centrifuge tube and 105 manually mixed before being centrifuged again for $2 \min \left(20^{\circ} \mathrm{C}, 9,500 \mathrm{RCF}\right)$. The final extract was 106 diluted 10 times in ultrapure water $+0.1 \%$ FA before injection in LC-MS/MS.

\subsection{Miniaturized protocol}

109 In order to make the analysis of small organisms (e.g., insect larvae, small fish) possible, a 110 miniaturized protocol (MP) was developed (Fig. 1). For this MP, a $2 \mathrm{~mL}$ polypropylene centrifuge 111 tube was filled with $30 \mathrm{mg}$ of matrix spiked with $50 \mu \mathrm{L}$ of a mix solution containing all analytes $112\left(30 \mu \mathrm{g} . \mathrm{L}^{-1}\right)$ to constitute artificial samples (concentrations and volumes used specifically for 113 validation are given in section 2.6). Before extraction, the added solvent was evaporated under gentle 114 nitrogen flux for $10 \mathrm{~min}$. Next, $0.5 \mathrm{~mL}$ of LC-MS water was added, and the whole sample was 115 shaken for $10 \mathrm{~min}$ at $16 \mathrm{~Hz}$ using Geno/Grinder. The tube was then completed with $1 \mathrm{~mL}$ of $\mathrm{ACN}+$ 
$1160.2 \% \mathrm{FA}$ and $0.5 \mathrm{~mL}$ of heptane before being shaken again for $10 \mathrm{~min}$ at $16 \mathrm{~Hz}$. It was centrifuged

117 for $5 \mathrm{~min}$ at $20^{\circ} \mathrm{C}$ and at 9,500 RCF. Then, $0.6 \mathrm{~mL}$ of the lower layer (ACN/water mix) was sampled

118 and dehydrated in a new centrifuge tube containing $0.3 \mathrm{~g}$ of $\mathrm{MgSO}_{4}$ and 3 zirconium oxide $3 \mathrm{~mm}$

119 grinding balls (Fisher Scientific, Illkirch, FR). Grinding balls were used to break up crystals formed

120 in these small tubes, which slow down the dehydration process and lead to poor recoveries for the 121 most polar analytes (e.g. -ESA or -OXA TPs). The tube was shaken for $1 \mathrm{~min}$ at $16 \mathrm{~Hz}$ to favor the 122 reaction and was centrifuged again at 9,500 RCF and $20^{\circ} \mathrm{C}$ for 2 min. Finally, the extract was diluted 12310 times in ultrapure water $+0.1 \%$ FA before injection in LC-MS/MS.

126 The development of the LC-MS/MS method was described in Dufour et al. (2020). Analysis of the 12741 PPP residues was performed using a 1290 Infinity UPLC system (Agilent Technologies, Massy, 128 FR) coupled with a 5500 QTRAP mass spectrometer (Sciex, Villebon-sur-Yvette, FR) in both 129 positive and negative modes using electrospray ionization. Forty microliters of sample was injected, 130 and separation was performed at $0.4 \mathrm{~mL} \cdot \mathrm{min}^{-1}$ and at $50^{\circ} \mathrm{C}$ on an XSelect ${ }^{\circledR} \mathrm{HSS} \mathrm{T} 3$ column $(2.1 \times$ $131150 \mathrm{~mm}, 2.5 \mu \mathrm{m}$, Waters, Saint Quentin-en-Yvelines, FR). The column was protected with a 132 KrudKatcher Ultra filter (Phenomenex, Le Pecq, FR) and an XSelect ${ }^{\circledR}$ HSS T3 precolumn $(2.1 \times 5$ $133 \mathrm{~mm}, 2.5 \mu \mathrm{m}$, Waters, Saint Quentin-en-Yvelines, FR). Ultrapure water $+0.1 \% \mathrm{FA}(\mathrm{A})$ and ACN + $1340.1 \%$ FA (B) were used as mobile phases in positive mode, while $1 \mathrm{mM}$ ammonium acetate in 135 ultrapure water (A) and ACN (B) were used in negative mode. The gradient was the same for both 136 methods: it started with $10 \%$ B for $1 \mathrm{~min}$, increased to $100 \% \mathrm{~B}$ over 7 min and held for 6 min, then 137 decreased back to $10 \% \mathrm{~B}$ over $1 \mathrm{~min}$ and held for $4 \mathrm{~min}$. The temperatures of the mass spectrometer 138 source, the nebulizer gas pressure, and heating gas pressure were set at $550^{\circ} \mathrm{C}, 40 \mathrm{psi}$, and $50 \mathrm{psi}$, 139 respectively. Ion spray voltages were $5500 \mathrm{~V}$ for positive ionization and $-4500 \mathrm{~V}$ for negative 140 ionization. Analytes and analytical parameters are available in Table S1. 
143 The MP was validated for the 41 molecules (21 PPPs and 20 TPs) for the fish matrix, using matrix144 matched calibration and following European guidance recommendations (European Commission 145 DG-SANTE 2019). The reference matrix spiked at 6 different concentration levels, namely 1 (C1), 2 146 (C2), 5 (C3), $10(\mathrm{C} 4), 15(\mathrm{C} 5)$, and 20 (C6) times the initial concentration (C1) (available in Table 147 1), and a protocol blank (C0), made up with reference matrix only, were extracted 5 times following 148 the whole MP to validate response linearity. The matrix was spiked at C2, C4, and C6 before 149 extraction and the corresponding areas were compared to the matrix spiked after extraction to 150 calculate ERs. The areas in the matrix spiked after extraction were also compared to those of 151 standard solutions of equivalent concentrations to calculate matrix effects (MEs). ER and ME 152 calculations are available in Supplementary information (SI). Inter-day precision was determined 153 over 5 days with the daily extraction in triplicate of one of the following concentration levels: C2 (n $154=3), \mathrm{C} 4(\mathrm{n}=2)$, and C6 $(\mathrm{n}=3)$.

155 Because only low masses of the reference MI matrix were available, the validation of the method for 156 MIs could not follow European guidelines (European Commission DG-SANTE 2019). Two 157 triplicates of matrix spiked at $\mathrm{C} 4$ and 2 protocol blanks were extracted on 2 different days to assess 158 protocol performance on this specific matrix. The limits of quantification (LOQs) were estimated to 159 be 10 times the signal-to-noise ratio on C4 samples. No ER estimation could be performed but 160 recoveries (RECs, Eq. 3 in SI), which reflect the trueness of the method, were calculated instead for 161 each molecule on the $\mathrm{C} 4$ samples $(\mathrm{n}=6)$, using matrix-matched calibration (C1 to $\mathrm{C} 6)$. 162 Chromatograms of both reference matrices spiked with monitored molecules at concentration C6 are 163 available in SI (Fig. S1). 
The developed miniaturized method was applied to 17 fish from 3 different species and 19 MI samples from 6 different taxa (see Section 2.2 for details) to characterize contamination in field samples. Following European guidelines (European Commission DG-SANTE 2019), quantification was performed with a 6-point matrix-matched calibration curve (described in Section 2.6). A 170 protocol blank and a reference matrix spiked at C2 for fish or C4 for MIs were extracted with each 171 sample series to avoid false positives and control RECs of each extraction series. When protocol 172 blanks showed contamination, the LOQs were increased to 3 times their quantified concentrations to 173 avoid false positives.

\subsection{Statistical analysis}

176 Isotope-labeled standards (D11-acetochlor, D5-acetochlor-ESA， D5-atrazine, D5-atrazine-2177 hydroxy, D6-bentazone, D4-carbendazim, 13C-fipronil, D4-imidacloprid, D3-isoproturon, D5178 metazachlor, D6-metazachlor-ESA, D10-simazine, D9-tebuconazole, D5-terbutryn) were introduced 179 into the MP in parallel with the analytes in the artificial samples, or instead of them for the analysis 180 of the field samples ( $50 \mu \mathrm{L}$ of a $30 \mu \mathrm{g} . \mathrm{L}^{-1}$ mix solution). They are too few and do not cover all the 181 chemical families researched to be used as internal standards, or they would probably have led to a 182 decrease of the accuracy and an increase of uncertainties (Han et al., 2018; Lehotay et al., 2018). 183 However, they can be used for evaluating the complexity of the matrices analyzed and tracing matrix 184 effects.

185 The area ratio between the reference matrix and the field samples was calculated for each 186 isotopically labeled standard. This parameter allowed to evaluate matrix complexity because 187 quantities introduced in all samples were the same. Principal component analyses (PCAs) were 188 performed on this ratio, for both fish and MIs, to evaluate if clusters of matrix complexity could be 189 determined based on species (fish) and taxonomic groups (MIs). PCAs were based on Pearson 190 regression $(\alpha=0.05)$. All statistical analyses and graphical PCA illustrations were performed using 
191 the software R (v. 4.0.0, (C) The R Foundation, 2020) with the following packages: "ggplot2"

192 (Wickham 2016), “factoextra" (Kassambara and Mundt 2020), "FactoMineR” (Lê et al. 2008), and

193 "RColorBrewer" (Neuwirth 2014).

\section{Results and discussion}

\subsection{Performance comparison between the initial protocol and the miniaturized protocol}

197 The IP and the MP were applied to a fish matrix $(n=5)$ with a C4 concentration level to assess

198 protocol performance (ERs and LOQs). The results are shown in Fig. 2. ERs ranged from 53\% 199 (terbutryn) to $103 \%$ (benzamide) with the IP and from $50 \%$ (prosulfocarb) to $120 \%$ (methsulfuron200 methyl) with the MP. According to European guidance recommendations (European Commission 201 DG-SANTE 2019), the ERs were considered good $(70 \%<$ ERs $<120 \%)$ for 39 and 38 molecules, 202 respectively. They were similar for both protocols, with a slight advantage for the MP. The most noticeable increases in ER were observed for desethylterbuthylazine-hydroxy (61\% to $97 \%$ for IP and MP, respectively), terbuthylazine ( $73 \%$ to $87 \%$ ), and terbutryn (53\% to $69 \%)$. The only outlier that did not benefit from the change in protocol was prosulfocarb with respective ERs of 54\% and $20650 \%$. LOQs ranged from 0.1 (fipronil, fipronil sulfone, metolachlor) to $221.8 \mathrm{ng}^{-1} \mathrm{dw}$

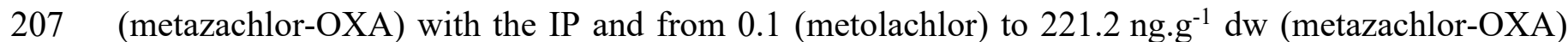
for the MP. Fourteen molecules showed LOQs of up to $10 \mathrm{ng} \cdot \mathrm{g}^{-1} \mathrm{dw}$ for the IP, as against 18

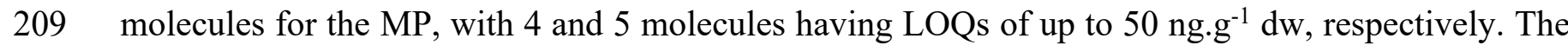
210 LOQs were very similar for both protocols, following a near-perfect linear regression $\left(\mathrm{R}^{2}=0.958\right)$. 211 However, they were on average 1.4 times higher with the MP than with the IP. As proportions of 212 reactants were conserved between the two protocols, obtaining similar performance results in terms 213 of LOQ and ER did not come as a surprise. Miniaturizing the IP yielded equivalent ERs and LOQs, 214 and allowed trace-level quantification of pesticide residues using $30 \mathrm{mg}$ instead of $500 \mathrm{mg}$ of matrix. 
217 The performance of the MP was fully evaluated for fish, as described in Section 2.6. The results are

218 shown in Table 1. Linear regression was determined for each molecule and $\mathrm{R}^{2}$ values were always 219 greater than 0.99 . Only 6 chemicals out of the 41 tested had $\mathrm{R}^{2}$ values below 0.99: acetochlor-OXA 220 (0.987), chlorotoluron (0.988), fenthion (0.950), flufenacet-ESA (0.987), metolachlor-ESA (0.989), 221 and terbutryn (0.989). However, second-order polynomial regressions were more adapted for those 222 molecules and their $\mathrm{R}^{2}$ values were found to be $0.994,0.996,0.991,0.992,0.999,0.993$, and 0.996 , 223 respectively.

224 Among the 41 targeted substances, 38 had LOQs lower than or equal to 60 ng.g $\mathrm{g}^{-1} \mathrm{dw}$, including 19 225 below $10 \mathrm{ng} \cdot \mathrm{g}^{-1} \mathrm{dw}$. Taking into account the dehydration of the matrix $(82 \% \pm 11 \%)$, these limits 226 corresponded to about 2 and 10 ng.g ${ }^{-1} \mathrm{ww}$, respectively. The overall performance was consistent 227 with that reported in the literature (Lazartigues et al. 2011; Kaczyński et al. 2017; Inostroza et al. 228 2017; Barbieri et al. 2019) although some LOQs were higher probably because of the low matrix 229 masses used to perform the extraction ( 0.9 to $10 \mathrm{~g}$ in the literature, as against $0.03 \mathrm{~g}$ in the present 230 study).

231 MEs ranged from $-77 \%$ (fenthion) to 131\% (imidacloprid-desnitro). Signal suppression was observed 232 for 11 molecules and signal enhancement concerned 8 substances (out of a -20/+20 range). This was 233 consistent with other studies reporting that signal suppression is the most commonly observed ME in 234 complex matrices (Lazartigues et al. 2011; Barbieri et al. 2019). The monitoring of this parameter 235 was important for validating the method even though matrix-matched calibration is supposed to 236 compensate for those effects.

237 ERs at C2 ranged from 57\% (prosulfocarb) to 108\% (TCP). According to the European guidelines 238 (European Commission DG-SANTE 2019) 35 of the 42 molecules presented good ERs (between $23970 \%$ and $120 \%$ ), including 12 of up to $80 \%$. At C4, acceptable ERs for fish and MI matrices were 240 obtained for 31 and 25 molecules, respectively. The inter-day precision was considered good for 32 
241 chemicals at C2 according to the European guidelines previously mentioned $(<20 \%)$. This

242 variability tended to decrease for higher concentration levels as the inter-day precision was lower

243 than or equal to $20 \%$ for 31 molecules at $\mathrm{C} 4$, which is in agreement with European guidelines

244 (European Commission DG-SANTE 2019). Moreover, if we leave aside the nature of the tested

245 matrix, the inter-day precision is better with IP (Dufour et al., 2020) than with MP. This was most

246 probably due to the decrease of the sample mass which led to an increase of the measurement

247 uncertainties, as shown by Han et al. (2018) and Lehotay et al. (2018) on food samples towards

248 pesticide contaminations. The developed analytical method was suitable for accurate quantification,

249 except for fenthion for which inter-day precision was of up to $50 \%$ for the 3 tested concentration

250 levels.

251 A signal-to-noise ratio of more than 3 was observed in protocol blanks for acetochlor-alachlor-ESA, 252 bentazon, benzamide, boscalid, CGA 50267, fipronil, fipronil sulfone, isoproturon, metolachlor, 253 prosulfocarb, and terbutryn. Contamination ranged from 0.1 to $8.8 \mathrm{ng}$ depending on the molecule 254 considered. The quantification frequency in blanks was usually below $50 \%$, but reached $60 \%$ for 255 fipronil and prosulfocarb, while metolachlor and terbutryn were systematically quantified. The LOQs 256 were increased to 3 times the contamination levels for these molecules to ensure the reliability of the 257 method.

\subsection{Performance of the miniaturized protocol in macroinvertebrates}

260 Performance of the MP was good for fish and compatible with trace analysis, so the protocol was 261 tested on MI samples. As very low mass was available for the reference matrix (chironomid larvae), 262 only linearity, RECs, and LOQs were assessed (Fig. 3). The tested concentration domains, ERs, 263 LOQs, and blank contamination of each molecule are shown in Table S2. The quantification of most 264 molecules followed a linear regression with $\mathrm{R}^{2}$ values greater than 0.99 ; only fenthion (0.986), 265 flufenacet (0.943), and TCP (0.961) were slightly below, reaching 0.994, 0.961, and 0.992, 
respectively, when a second-order polynomial regression was applied. Protocol blanks were clean (n

$267=4)$ but traces $(\leq 0.8 \mathrm{ng})$ of dimethenamid-ESA, MCPA, and terbutryn were quantified 268 (quantification frequency below 0.5). LOQs ranged from 0.1 (fipronil, fipronil sulfone, metolachlor) 269 to 356 ng. $\mathrm{g}^{-1} \mathrm{dw}$ (metazachlor-OXA); taking into account the dehydration $(85 \%$ on average for this 270 matrix), the LOQs ranged from 0.015 to $53 \mathrm{ng} \cdot \mathrm{g}^{-1} \mathrm{ww}$. Among the 41 tested molecules, 29 had LOQs 271 below $10 \mathrm{ng} \cdot \mathrm{g}^{-1} \mathrm{dw}, 14$ of which being below $1 \mathrm{ng} \cdot \mathrm{g}^{-1} \mathrm{dw}$. These values were of the same order of 272 magnitude as those reported in the literature (Haroune et al. 2015; Althakafy et al. 2018; Miller et al. 273 2019). Most tested molecules had good RECs (80\%-120\%) and values above 120\% were obtained 274 with four of them (i.e., bentazone $122 \%$, boscalid $122 \%$, desethylterbutylazine-hydroxy $121 \%$, and 275 metazachlor-OXA 131\%). The latter values were close to the acceptable limits, except for 276 metazachlor-OXA for which a correction was necessary for the quantification of MI field samples. It 277 confirmed that most pesticide residues can be monitored in complex biotic matrices with low matrix 278 masses using a single method that provides equivalent levels of performance.

\subsection{Field samples}

281 In order to validate the performance of the method, 17 fish (3 species) and 19 MI (6 orders) samples 282 were collected and analyzed with the MP. All samples were spiked before extraction with 14 283 isotopically labeled standards (see section 2.8). The areas of these molecules were compared 284 between field samples and reference matrices. The average ratio ranged from 0.9 (D5-acetochlor285 ESA, D6-bentazone, D6-metazachlor-ESA, D5-atrazine-2-hydroxy, D9-tebuconazole) to 1.4 (D5286 terbutryn) for fish and from 0.8 (D5-acetochlor-ESA, D6-metazachlor-ESA) to 1.5 (D11-acetochlor) 287 for MIs. The relative standard deviation (\%RSD) was lower than $30 \%$ for all molecules, except for 288 D5-atrazine (34\%) and 13C-fipronil (32\%) in fish, and D5-acetochlor-ESA (50\%) in MIs. Taking 289 into account that a single matrix was used to quantify 3 different fish species, and another single 290 matrix for 6 different MI groups, these ratios close to 1 confirmed the potential for the protocol to be 
transposed to other biotic matrices with similar relative levels of fat and protein. PCAs performed on area ratios illustrated $77.6 \%$ and $66.5 \%$ of total variability for fish and MI matrices, respectively (Fig. 4). Clusters could be identified for fish, showing that differences in matrix complexity exist

294 between the 3 species, probably based on their physiological constitution. However, there was 295 considerable overlap between the clusters, indicating relatively similar responses for internal 296 standards. The same overlap was observed for MIs, confirming that the chosen reference matrix is 297 suitable for matrix-matched calibration. However, hindsight is relatively poor for Anisoptera, 298 Daphniidae, and Dytiscidae as their number of samples is $\leq 2$.

299 Concentrations monitored in field samples are shown in Table 2. Among the 40 targeted molecules 300 (fenthion being excluded because of its unreliability, see Section 3.3), 7 were detected: benzamide, 301 imidacloprid-desnitro, fipronil, imidacloprid, prosulfocarb, tebuconazole, and terbutryn. Benzamide, 302 imidacloprid-desnitro, and prosulfocarb were almost systematically quantified in fish (from 42 to $303237 \mathrm{ng} \cdot \mathrm{g}^{-1} \mathrm{dw}, 3 \mathrm{ng} \cdot \mathrm{g}^{-1} \mathrm{dw}$, and from 30 to $165 \mathrm{ng} \cdot \mathrm{g}^{-1} \mathrm{dw}$, respectively) and in MIs (from 62 to 438 $304 \mathrm{ng} \cdot \mathrm{g}^{-1} \mathrm{dw}$, from 2 to $6 \mathrm{ng} \cdot \mathrm{g}^{-1} \mathrm{dw}$, and from 15 to $29 \mathrm{ng} \cdot \mathrm{g}^{-1} \mathrm{dw}$, respectively). Considering the 305 dehydration ratio, the average quantified concentrations of these three molecules were of $21,<$ LOQ, 306 and 12 ng. $\mathrm{g}^{-1} \mathrm{ww}$ in fish, respectively, and of 26, 0.4, and $3 \mathrm{ng} \cdot \mathrm{g}^{-1} \mathrm{ww}$ in MIs, respectively.

307 Prosulfocarb is a herbicide known to drift away, leading to the contamination of non-target crops and 308 waterbodies (Devault et al. 2019). As it possesses a $\log \mathrm{P}$ of 4.5 , it is likely to accumulate in 309 organisms, which seemed to be the case in this study for MIs and fish. It has already been reported in 310 ponds at concentrations of up to $0.5 \mu \mathrm{g} . \mathrm{L}^{-1}$ (Gaillard et al. 2016a). Benzamide is a TP of folpet that 311 accumulates in both fish and MIs. Despite having a lower $\log \mathrm{P}$ value than prosulfocarb $(\log \mathrm{P}=$ 312 0.6), it was found in higher concentrations. Imidacloprid-desnitro, a TP of imidacloprid, was 313 quantified in $5 \%$ of the fish samples and in $42 \%$ of the MI samples, while the quantification 314 frequency of the active substance was $0 \%$ and $16 \%$, respectively. There is a lack of data in the 315 literature investigating the toxicity of imidacloprid-desnitro in aquatic organisms. Nevertheless, 
316 research revealed that it has lower toxicity than imidacloprid in bees (Suchail et al. 2001). It should

317 be noted that, in the present study, field sampling was carried out in May 2018. A few months later,

318 in September 2018, the outdoor use of the herbicide was banned by the European Commission, so

319 biotic concentrations are expected to decrease over time. However, the monitoring of TPs remain

320 relevant as they sometimes have higher environmental concentrations than their parent molecules,

321 and there is little evidence for their safety (Kiefer et al., 2019).

\section{4. Conclusion}

324 A miniaturized extraction protocol was successfully developed and applied to two complex matrices:

325 fish and MIs. It allowed a sensitive and consistent analysis of PPPs even when only low sample mass

326 was available. A decrease in the required mass of matrix slightly increased the LOQs of the MP in

327 fish compared to the IP, but final LOQs were still suitable for trace-level analysis with most below

32810 ng. $\mathrm{g}^{-1} \mathrm{dw}$. Moreover, ERs were in the range $70 \%-120 \%$ for 35 of the 41 molecules. The 329 transposition of IP to MP did not altered its performances. The application of this protocol in the 330 field has revealed low contamination of aquatic organisms, but it has also shown that they are 331 contaminated by a cocktail of molecules and TPs. The harmlessness of such a combination of 332 contaminants is not guaranteed, and it is important to take it into consideration in order to ensure the 333 good status of aquatic ecosystems. The herbicide prosulfocarb and the transformation product 334 benzamide were almost systematically quantified in both matrices. The MP, developed in this study, 335 represents a potential tool for the characterization of polar pesticides in small complex biotic 336 samples.

\section{Acknowledgments}

339 This project was funded by the "Office Français pour la Biodiversité". The authors sincerely thank 340 the fish farmers and owners for granting access to their ponds. They are also grateful to Alain Iurétig 
341 (sampling and pre-treatment, Univ. of Lorraine), Pamela Hartmeyer (pre-treatment, Univ. of

342 Lorraine), Aisha Nunoo (extractions, Univ. of Lorraine/ISA), and Maud Dessein-Lepasteur 343 (extractions and analysis, Univ. of Lorraine/ISA) for their work, as well as to Arnaud Chaumot and 344 Laura Garnero from the Ecotoxicology Team of the UR RIVERLY (INRAE, Centre de Lyon345 Villeurbanne) for providing chironomid larvae. The authors sincerely thank ABC Translation for the 346 proofreading work done.

\section{Funding Information:}

349 This project was funded by the "Office Français pour la Biodiversité".

\section{References}

352 Althakafy JT, Kulsing C, Grace MR, Marriott PJ (2018) Determination of selected emerging contaminants in freshwater invertebrates using a universal extraction technique and liquid chromatography accurate mass spectrometry. J Sep Sci 41:3706-3715. https://doi.org/10.1002/jssc.201800507

Anastassiades M, Lehotay SJ, Štajnbaher D, Schenck FJ (2003) Fast and Easy Multiresidue Method Employing Acetonitrile Extraction/Partitioning and "Dispersive Solid-Phase Extraction" for the Determination of Pesticide Residues in Produce. J AOAC Int 86:412-431. https://doi.org/10.1093/jaoac/86.2.412

Barbieri MV, Postigo C, Guillem-Argiles N, et al (2019) Analysis of 52 pesticides in fresh fish muscle by QuEChERS extraction followed by LC-MS/MS determination. Sci Total Environ 653:958-967. https://doi.org/10.1016/j.scitotenv.2018.10.289

Brain RA, Anderson JC (2019) The agro-enabled urban revolution, pesticides, politics, and popular culture: a case study of land use, birds, and insecticides in the USA. Environ Sci Pollut Res 26:21717-21735. https://doi.org/10.1007/s11356-019-05305-9 
Clasen B, Loro VL, Murussi CR, et al (2018) Bioaccumulation and oxidative stress caused by pesticides in Cyprinus carpio reared in a rice-fish system. Sci Total Environ 626:737-743. https://doi.org/10.1016/j.scitotenv.2018.01.154

Devault DA, Guillemin J-P, Millet M, et al (2019) Prosulfocarb at center stage! Environ Sci Pollut Res 1-15. https://doi.org/10.1007/s11356-019-06928-8

Dufour V, Wiest L, Slaby S, et al (2020) Development of a simple multiresidue extraction method for the quantification of a wide polarity range list of pesticides and transformation products in eggs by liquid chromatography and tandem mass spectrometry. J Chromatogr A 1628:461447. https://doi.org/10.1016/j.chroma.2020.461447

European Commission DG-SANTE (2019) Analytical Quality Control and Method Validation Procedures for Pesticide Residues Analysis in Food and Feed, N SANTE/12682/2019. 49

Four B, Thomas M, Danger M, et al (2019) Using stable isotope approach to quantify pond dam impacts on isotopic niches and assimilation of resources by invertebrates in temporary streams: a case study. Hydrobiologia 834:163-181. https://doi.org/10.1007/s10750-019-3920-0

Gaillard J, Thomas M, Iuretig A, et al (2016a) Barrage fishponds: Reduction of pesticide concentration peaks and associated risk of adverse ecological effects in headwater streams. J Environ Manage 169:261-271. https://doi.org/10.1016/j.jenvman.2015.12.035

Gaillard J, Thomas M, Lazartigues A, et al (2016b) Potential of barrage fish ponds for the mitigation of pesticide pollution in streams. Environ Sci Pollut Res 23:23-35. https://doi.org/10.1007/s11356-015-5378-6

Geiger F, Bengtsson J, Berendse F, et al (2010) Persistent negative effects of pesticides on biodiversity and biological control potential on European farmland. Basic Appl Ecol 11:97-105. https://doi.org/10.1016/j.baae.2009.12.001

Giroud B, Vauchez A, Vulliet E, et al (2013) Trace level determination of pyrethroid and neonicotinoid insecticides in beebread using acetonitrile-based extraction followed by analysis 
with ultra-high-performance liquid chromatography-tandem mass spectrometry. J Chromatogr

Golge O, Koluman A, Kabak B (2018) Validation of a Modified QuEChERS Method for the Determination of 167 Pesticides in Milk and Milk Products by LC-MS/MS. Food Anal Methods

Han, L., Lehotay, S.J., Sapozhnikova, Y., 2018. Use of an Efficient Measurement Uncertainty Approach To Compare Room Temperature and Cryogenic Sample Processing in the Analysis of 11:1122-1148. https://doi.org/10.1007/s12161-017-1066-0 Chemical Contaminants in Foods. J. Agric. Food Chem. 66, 4986-4996. https://doi.org/10.1021/acs.jafc.7b04359

Haroune L, Cassoulet R, Lafontaine M-P, et al (2015) Liquid chromatography-tandem mass spectrometry determination for multiclass pesticides from insect samples by microwave-assisted solvent extraction followed by a salt-out effect and micro-dispersion purification. Anal Chim Acta 891:160-170. https://doi.org/10.1016/j.aca.2015.07.031

Inostroza PA, Massei R, Wild R, et al (2017) Chemical activity and distribution of emerging pollutants: Insights from a multi-compartment analysis of a freshwater system. Environ Pollut 231:339-347. https://doi.org/10.1016/j.envpol.2017.08.015

Kaczyński P, Łozowicka B, Perkowski M, Szabuńko J (2017) Multiclass pesticide residue analysis in fish muscle and liver on one-step extraction-cleanup strategy coupled with liquid chromatography tandem mass spectrometry. Ecotoxicol Environ Saf 138:179-189. https://doi.org/10.1016/j.ecoenv.2016.12.040

413 Kiefer, K., Müller, A., Singer, H., Hollender, J., 2019. New relevant pesticide transformation 414 products in groundwater detected using target and suspect screening for agricultural and urban 415 micropollutants with LC-HRMS. Water Res. 165 , 114972. 
417 Knoll S, Rösch T, Huhn C (2020) Trends in sample preparation and separation methods for the 418 analysis of very polar and ionic compounds in environmental water and biota samples. Anal Bioanal Chem 412:6149-6165. https://doi.org/10.1007/s00216-020-02811-5

420 Koesukwiwat U, Lehotay SJ, Miao S, Leepipatpiboon N (2010) High throughput analysis of 150 421 pesticides in fruits and vegetables using QuEChERS and low-pressure gas chromatographytime-of-flight mass spectrometry. J Chromatogr A 1217:6692-6703. https://doi.org/10.1016/j.chroma.2010.05.012

424 Konwick BJ, Garrison AW, Black MC, et al (2006) Bioaccumulation, biotransformation, and metabolite formation of fipronil and chiral legacy pesticides in rainbow trout. Environ Sci Technol 40:2930-2936. https://doi.org/10.1021/es0600678

Lazartigues A, Wiest L, Baudot R, et al (2011) Multiresidue method to quantify pesticides in fish

430 Lê S, Josse J, Husson F (2008) FactoMineR : An R Package for Multivariate Analysis. J Stat Softw 25:. https://doi.org/10.18637/jss.v025.i01

432 Lehotay, S.J., Han, L., Sapozhnikova, Y., 2018. Use of a quality control approach to assess measurement uncertainty in the comparison of sample processing techniques in the analysis of pesticide residues in fruits and vegetables. Anal. Bioanal. Chem. 410, 5465-5479. 436 Lehotay SJ, Son KA, Kwon H, et al (2010) Comparison of QuEChERS sample preparation methods for the analysis of pesticide residues in fruits and vegetables. J Chromatogr A 1217:2548-2560.

439 Lichtmannegger K, Fischer R, Steemann FX ave., et al (2015) Alternative QuEChERS-based modular approach for pesticide residue analysis in food of animal origin. Anal Bioanal Chem 
442 Macchi P, Loewy RM, Lares B, et al (2018) The impact of pesticides on the macroinvertebrate 443 community in the water channels of the Río Negro and Neuquén Valley, North Patagonia 444 (Argentina). Environ Sci Pollut Res 25:10668-10678. https://doi.org/10.1007/s11356-018$445 \quad 1330-\mathrm{x}$

446 McLaughlin A, Mineau P (1995) The impact of agricultural practices on biodiversity. Agric Ecosyst Environ 55:201-212. https://doi.org/10.1016/0167-8809(95)00609-V

448 Miller TH, Ng KT, Bury ST, et al (2019) Biomonitoring of pesticides, pharmaceuticals and illicit 449 drugs in a freshwater invertebrate to estimate toxic or effect pressure. Environ Int 129:595-606. $450 \quad$ https://doi.org/10.1016/j.envint.2019.04.038

451 Neuwirth E (2014) RColorBrewer: ColorBrewer Palettes

452 Nowell LH, Moran PW, Schmidt TS, et al (2018) Complex mixtures of dissolved pesticides show 453 potential aquatic toxicity in a synoptic study of Midwestern U.S. streams. Sci Total Environ 613-614:1469-1488. https://doi.org/10.1016/j.scitotenv.2017.06.156

455 Oliveira FA da S, Pereira ENC, Gobbi JM, et al (2018) Multiresidue method for detection of 456 pesticides in beef meat using liquid chromatography coupled to mass spectrometry detection (LC-MS) after QuEChERS extraction. Food Addit Contam Part A 35:94-109.

459 Reemtsma T, Berger U, Arp HPH, et al (2016) Mind the Gap: Persistent and Mobile Organic 460 Compounds-Water Contaminants That Slip Through. Environ Sci Technol 50:10308-10315. https://doi.org/10.1021/acs.est.6b03338

462 Roche H, Vollaire Y, Martin E, et al (2009) Rice fields regulate organochlorine pesticides and PCBs 463 in lagoons of the Nature Reserve of Camargue. Chemosphere 75:526-533. https://doi.org/10.1016/j.chemosphere.2008.12.009

465 Rostron C (2010) Review of Environmental Contamination and Toxicology Volume 204. Springer 
467 Sanganyado, E., Bi, R., Teta, C., Buruaem Moreira, L., Yu, X., Yajing, S., Dalu, T., Rajput, I.R., 468 Liu, W., 2020. Toward an integrated framework for assessing micropollutants in marine 469 mammals: Challenges, progress, and opportunities. Crit. Rev. Environ. Sci. Technol. 0, 1-48. $470 \quad$ https://doi.org/10.1080/10643389.2020.1806663

471 Sinclair CJ, Boxall ABA (2003) Assessing the Ecotoxicity of Pesticide Transformation Products. 472 Environ Sci Technol 37:4617-4625. https://doi.org/10.1021/es030038m

473 Slaby S, Marin M, Marchand G, Lemiere S (2019) Exposures to chemical contaminants: What can 474 we learn from reproduction and development endpoints in the amphibian toxicology literature? Environ Pollut 248:478-495. https://doi.org/10.1016/j.envpol.2019.02.014

Song N-E, Lee JY, Mansur AR, et al (2019) Determination of 60 pesticides in hen eggs using the

Stanton RL, Morrissey CA, Clark RG (2018) Analysis of trends and agricultural drivers of farmland

bird declines in North America: A review. Agric Ecosyst Environ 254:244-254. https://doi.org/10.1016/j.agee.2017.11.028 QuEChERS procedure followed by LC-MS/MS and GC-MS/MS. Food Chem 298:125050. https://doi.org/10.1016/j.foodchem.2019.125050

Suchail S, Guez D, Belzunces LP (2001) Discrepancy between acute and chronic toxicity induced by imidacloprid and its metabolites in Apis mellifera. Environ Toxicol Chem 20:2482-2486. https://doi.org/10.1002/etc.5620201113

Tousova Z, Oswald P, Slobodnik J, et al (2017) European demonstration program on the effect-based and chemical identification and monitoring of organic pollutants in European surface waters. Sci Total Environ 601-602:1849-1868. https://doi.org/10.1016/j.scitotenv.2017.06.032

Wickham H (2016) GGPLOT2: Elegant Graphics for Data Analysis. Springer-Verlag New York 489 


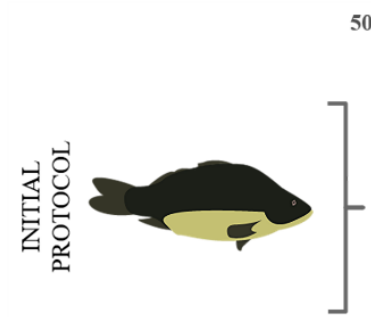

$50 \mathrm{~mL}$ centrifuge tube $+500 \mathrm{mg}$ sample
$+5 \mathrm{~mL}$ water
$+10 \mathrm{~mL} \mathrm{ACN} 0.2 \% \mathrm{AF}$
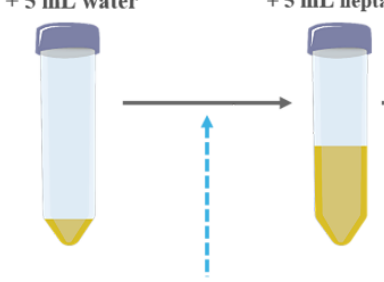

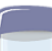

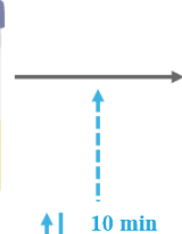

$\uparrow 10 \mathrm{~min}$

$$
\text { †ा } 10 \mathrm{~min}
$$

त $5 \mathrm{~min}$

ㅅ $9500 \mathrm{RC}$ $2.5 \mathrm{~g} \mathrm{MgSO}_{4}$
$+6 \mathrm{~mL}$ infranatant

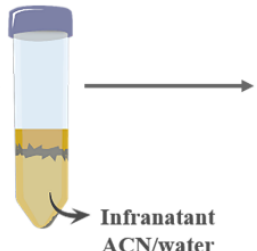

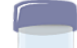

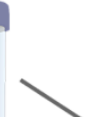

$100 \mu \mathrm{L}$ final extract

$+900 \mu \mathrm{L}$ water $(0.1 \% \mathrm{AF})$

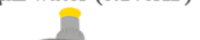

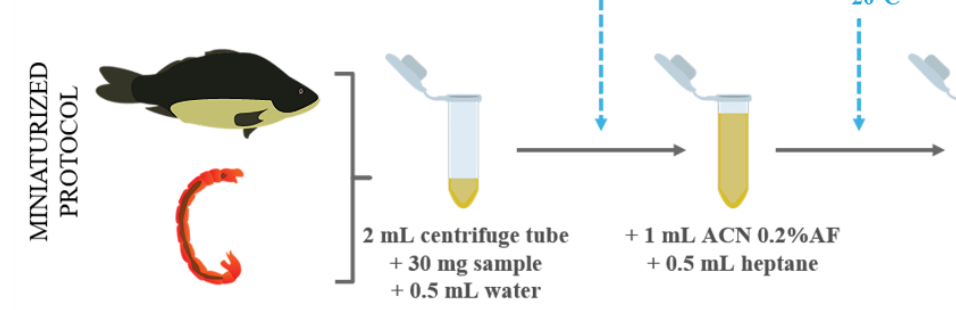

$+0.5 \mathrm{~mL}$ water

492 Fig. 1. Step comparison between the initial and miniaturized protocol (ACN: acetonitrile, FA: Formic acid) 

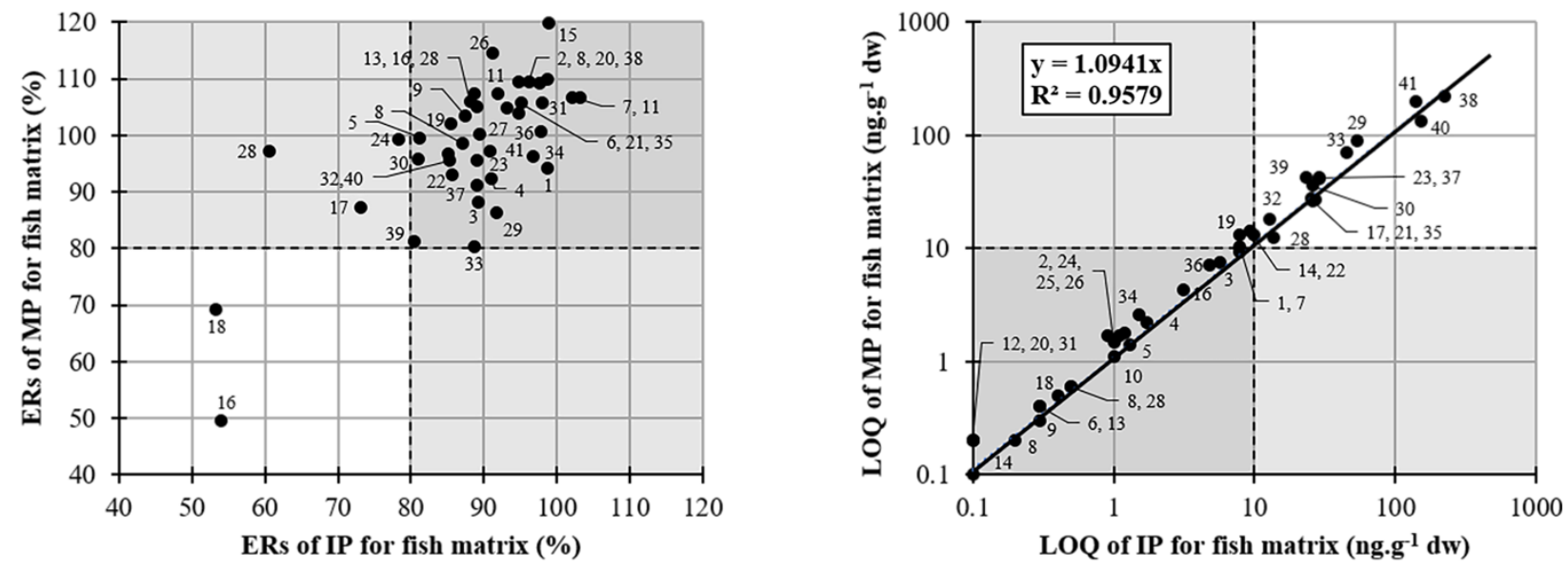

496 Fig. 2. Comparison between the initial (IP) and miniaturized protocol (MP) in terms of extraction rates (ERs) and limits of quantification (LOQs) obtained for fish blank matrix spiked at $\mathrm{C} 4(\mathrm{n}=5)$; see Table 1 for the molecules associated with the numbers 


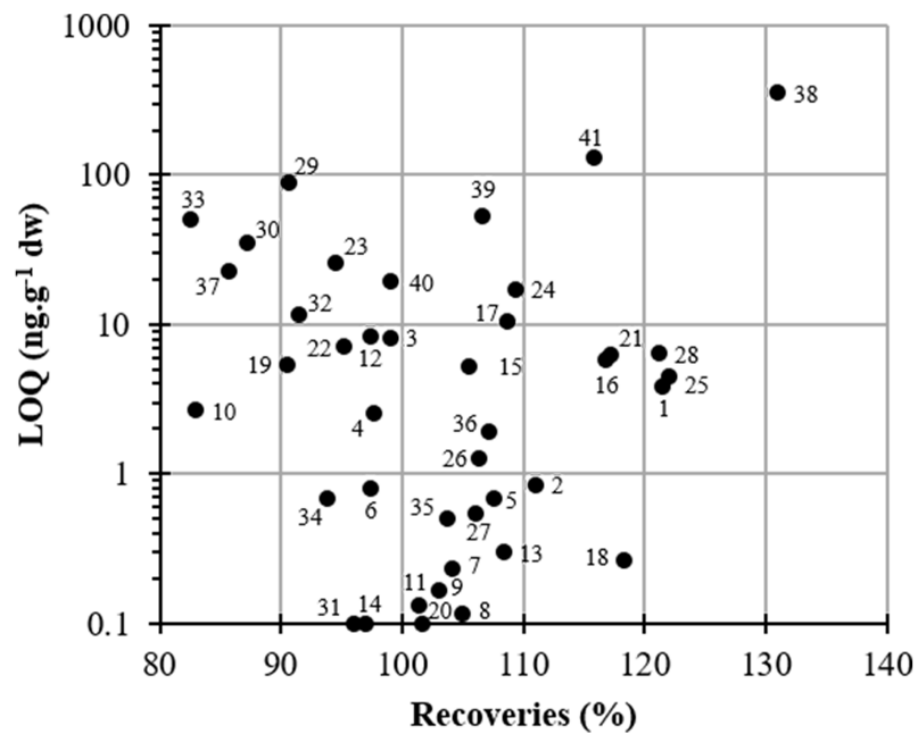

501

502 Fig. 3. Quantification recoveries (\%) and limits of quantification (LOQs) (ng.g ${ }^{-1} \mathrm{dw}$ ) obtained for 503 macroinvertebrates spiked at $\mathrm{C} 4(\mathrm{n}=6)$; see Table 1 for the molecules associated with the numbers 504 

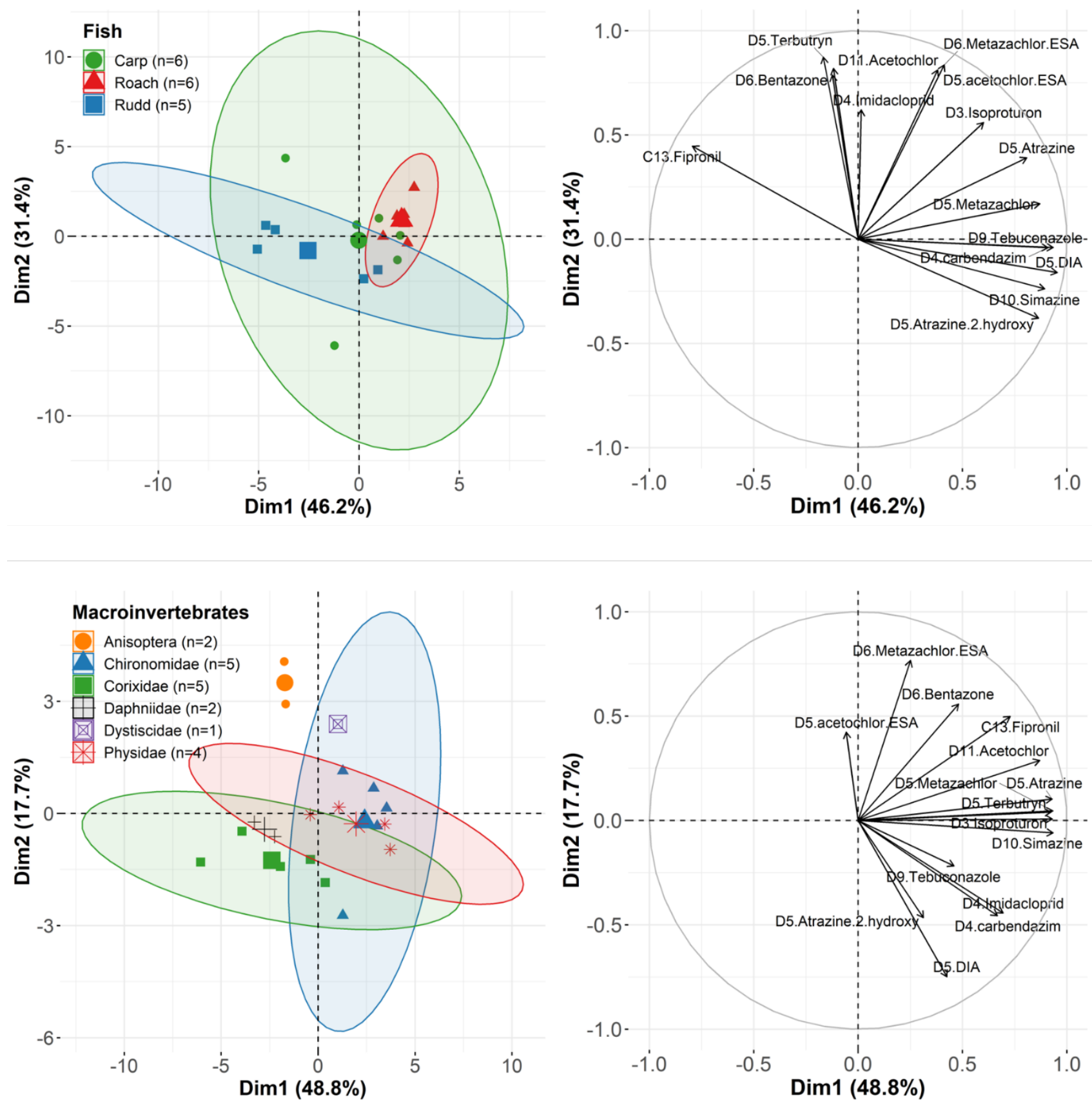

507 Fig. 4. Representation of isotope-labeled standard area ratios between reference and field samples for fish and 508 macroinvertebrates; PCA based on Pearson regression $(\alpha=0.05)$

\section{(USE COLORS FOR THIS FIGURE)}




\begin{tabular}{|c|c|c|c|c|c|c|c|c|c|c|c|c|c|}
\hline \multirow{2}{*}{$n^{\circ}$} & \multirow{2}{*}{ Chemicals } & \multirow{2}{*}{$\begin{array}{c}\text { Domain } \\
\left(n g \cdot g^{-1}\right. \\
\text { dw) }\end{array}$} & \multirow{2}{*}{$\begin{array}{c}r^{2} \pm \\
\% \circ R S D \\
(n=5)\end{array}$} & \multirow{2}{*}{$\begin{array}{l}\text { LOQ } \\
\text { (ng.g- } \\
{ }^{1} \text { dw) }\end{array}$} & \multirow{2}{*}{$\begin{array}{l}\text { Matrix } \\
\text { effect } \pm \\
\text { SD }(\%)\end{array}$} & \multicolumn{3}{|c|}{ Recovery $\pm \%$ RSD $(\%)$} & \multicolumn{3}{|c|}{$\begin{array}{c}\text { Inter-day precision } \\
(\% \text { RSD })\end{array}$} & \multicolumn{2}{|c|}{ Blanks $(\mathrm{n}=5)$} \\
\hline & & & & & & $\begin{array}{c}\mathrm{C} 2 \\
(\mathrm{n}=6)\end{array}$ & $\begin{array}{c}\mathrm{C} 4 \\
(\mathrm{n}=3)\end{array}$ & $\begin{array}{c}\text { C6 } \\
(n=6)\end{array}$ & $\begin{array}{c}\mathrm{C} 2 \\
(\mathrm{n}=5)\end{array}$ & $\begin{array}{c}\mathrm{C} 4 \\
(\mathrm{n}=5)\end{array}$ & $\begin{array}{c}\text { C6 } \\
(\mathrm{n}=5)\end{array}$ & $\begin{array}{c}\text { Min - } \\
\operatorname{Max}(n g)\end{array}$ & QF \\
\hline & Fungicides & & & & & & & & & & & & \\
\hline 1 & Boscalid & $60-1200$ & $0.996(4)$ & 60 & $-6 \pm 12$ & $80 \pm 15$ & $87 \pm 4$ & $93 \pm 8$ & 27 & 18 & 23 & $5.1-5.1$ & 0.2 \\
\hline \multirow[t]{2}{*}{2} & Tebuconazole & $3-60$ & $0.993(2)$ & 3 & $-18 \pm 15$ & $69 \pm 20$ & $98 \pm 17$ & $89 \pm 8$ & 26 & 15 & 24 & - & - \\
\hline & Herbicides & & & & & & & & & & & & \\
\hline 3 & Acetochlore & $60-1200$ & $0.995(4)$ & 60 & $-2 \pm 14$ & $76 \pm 12$ & $77 \pm 2$ & $80 \pm 4$ & 27 & 20 & 22 & - & - \\
\hline 4 & Alachlor & $30-600$ & $0.995(3)$ & 30 & $-10 \pm 12$ & $77 \pm 9$ & $79 \pm 6$ & $79 \pm 7$ & 24 & 19 & 22 & - & - \\
\hline 5 & Atrazine & $3-60$ & $0.996(2)$ & 3 & $-31 \pm 12$ & $74 \pm 13$ & $82 \pm 5$ & $86 \pm 7$ & 22 & 18 & 20 & - & - \\
\hline 6 & Bentazon & $3-60$ & $0.992(8)$ & 3 & $-8 \pm 16$ & $69 \pm 33$ & $88 \pm 6$ & $88 \pm 3$ & 22 & 17 & 18 & $0.1-0.1$ & 0.2 \\
\hline 7 & Chlorotoluron & $6-120$ & $\begin{array}{c}0.988 \\
(14)\end{array}$ & 6 & $-20 \pm 16$ & $83 \pm 19$ & $86 \pm 10$ & $92 \pm 7$ & 20 & 21 & 62 & - & - \\
\hline 8 & Dimethachlor & $6-120$ & $0.996(2)$ & 6 & $-14 \pm 17$ & $78 \pm 22$ & $89 \pm 5$ & $89 \pm 3$ & 27 & 21 & 21 & - & - \\
\hline 9 & Dimethenamide & $6-120$ & $0.995(1)$ & 6 & $-20 \pm 14$ & $76 \pm 25$ & $86 \pm 5$ & $88 \pm 10$ & 22 & 20 & 22 & - & - \\
\hline 10 & Flufenacet & $6-120$ & $0.996(4)$ & 6 & $-6 \pm 17$ & $74 \pm 18$ & $85 \pm 6$ & $91 \pm 5$ & 27 & 18 & 21 & - & - \\
\hline 11 & Isoproturon & $3-60$ & $0.993(4)$ & 3 & $-23 \pm 15$ & $77 \pm 18$ & $92 \pm 9$ & $93 \pm 7$ & 22 & 18 & 19 & 0.1 & 0.2 \\
\hline 12 & MCPA & $30-600$ & $0.993(4)$ & 30 & $16 \pm 9$ & $72 \pm 29$ & $89 \pm 1$ & $86 \pm 7$ & 26 & 21 & 21 & - & - \\
\hline 13 & Metazachlor & $3-60$ & $0.992(5)$ & 3 & $-10 \pm 16$ & $83 \pm 19$ & $90 \pm 10$ & $92 \pm 9$ & 25 & 18 & 20 & - & - \\
\hline 14 & Metolachlor & $3-60$ & $0.997(3)$ & 3 & $-6 \pm 12$ & $88 \pm 8$ & $82 \pm 12$ & $83 \pm 4$ & 26 & 18 & 19 & $0.1-0.2$ & 1.0 \\
\hline 15 & Metsulfuron-methyl & $30-600$ & $0.994(5)$ & 30 & $48 \pm 29$ & $71 \pm 31$ & $101 \pm 7$ & $106 \pm 7$ & 27 & 21 & 21 & - & - \\
\hline 16 & Prosulfocarb & $30-600$ & $0.99(6)$ & 30 & $-57 \pm 16$ & $\begin{array}{c}102 \pm \\
63\end{array}$ & $36 \pm 11$ & $45 \pm 13$ & 23 & 24 & 23 & $0-8.8$ & 0.6 \\
\hline 17 & Terbuthylazine & $3-60$ & $0.994(4)$ & 3 & $-41 \pm 23$ & $84 \pm 24$ & $67 \pm 16$ & $74 \pm 7$ & 19 & 17 & 21 & - & - \\
\hline \multirow[t]{2}{*}{18} & Terbutryn & $3-60$ & $0.989(7)$ & 3 & $-43 \pm 7$ & $86 \pm 26$ & $63 \pm 10$ & $66 \pm 6$ & 26 & 16 & 20 & $0.1-0.2$ & 1.0 \\
\hline & Insecticides & & & & & & & & & & & & \\
\hline 19 & Fenthion & $20-400$ & $0.95(76)$ & 80 & $-77 \pm 21$ & $87 \pm 33$ & $82 \pm 8$ & $\begin{array}{c}121 \pm \\
88\end{array}$ & 62 & 59 & 60 & - & - \\
\hline 20 & Fipronil & $3-60$ & $0.997(2)$ & 3 & $-13 \pm 8$ & $74 \pm 22$ & $85 \pm 5$ & $90 \pm 6$ & 23 & 16 & 19 & 0.1 & 0.6 \\
\hline 21 & Imidacloprid & $30-600$ & $0.993(8)$ & 30 & $19 \pm 11$ & $\begin{array}{c}101 \pm \\
70\end{array}$ & $94 \pm 6$ & $94 \pm 4$ & 27 & 19 & 23 & - & - \\
\hline
\end{tabular}




\begin{tabular}{|c|c|c|c|c|c|c|c|c|c|c|c|c|c|}
\hline & $\begin{array}{l}\text { Transformation } \\
\text { products }\end{array}$ & & & & & & & & & & & & \\
\hline 22 & Acetochlor OXA & $30-600$ & $\begin{array}{c}0.987 \\
(10)\end{array}$ & 30 & $27 \pm 12$ & $70 \pm 24$ & $76 \pm 10$ & $78 \pm 12$ & 27 & 19 & 24 & - & - \\
\hline 23 & $\begin{array}{l}\text { Alachlor-Acetochlor } \\
\text { ESA }\end{array}$ & $30-600$ & $0.993(5)$ & 30 & $33 \pm 11$ & $77 \pm 17$ & $69 \pm 5$ & $76 \pm 7$ & 34 & 18 & 22 & $0.5-0.5$ & 0.2 \\
\hline 24 & Atrazine-2-hydroxy & $3-60$ & $0.996(2)$ & 3 & $-3 \pm 16$ & $68 \pm 17$ & $83 \pm 8$ & $82 \pm 6$ & 26 & 18 & 19 & - & - \\
\hline 25 & Benzamide & $30-600$ & $0.991(5)$ & 30 & $61 \pm 93$ & $96 \pm 16$ & $\begin{array}{c}105 \pm \\
10\end{array}$ & $98 \pm 10$ & 16 & 18 & 22 & $0.2-0.3$ & 0.4 \\
\hline 26 & CGA 50267 & $3-60$ & $0.995(4)$ & 3 & $-10 \pm 13$ & $72 \pm 25$ & $92 \pm 3$ & $91 \pm 10$ & 25 & 19 & 19 & $0.2-0.2$ & 0.2 \\
\hline 27 & Desethylterbutylazine & $3-60$ & $0.995(3)$ & 3 & $-18 \pm 14$ & $75 \pm 18$ & $86 \pm 6$ & $89 \pm 5$ & 23 & 14 & 20 & - & - \\
\hline 28 & $\begin{array}{l}\text { Desethylterbutylazine } \\
\text {-OH }\end{array}$ & $50-1000$ & $0.994(4)$ & 50 & $-4 \pm 8$ & $71 \pm 20$ & $86 \pm 10$ & $77 \pm 10$ & 24 & 23 & 62 & - & - \\
\hline 29 & Dimethachlor ESA & $30-600$ & $0.994(3)$ & 60 & $10 \pm 12$ & $79 \pm 7$ & $67 \pm 14$ & $70 \pm 15$ & 29 & 18 & 22 & - & - \\
\hline 30 & Dimethenamide ESA & $30-600$ & $0.99(9)$ & 30 & $15 \pm 12$ & $87 \pm 25$ & $60 \pm 8$ & $69 \pm 11$ & 33 & 17 & 22 & - & - \\
\hline 31 & Fipronil sulfone & $3-60$ & $0.99(10)$ & 3 & $-43 \pm 21$ & $78 \pm 14$ & $82 \pm 7$ & $87 \pm 11$ & 27 & 15 & 22 & 0.1 & 0.6 \\
\hline 32 & Flufenacet ESA & $6-120$ & $\begin{array}{c}0.987 \\
(10)\end{array}$ & 12 & $11 \pm 15$ & $66 \pm 34$ & $64 \pm 7$ & $71 \pm 12$ & 42 & 13 & 24 & - & - \\
\hline 33 & Flufenacet OXA & $30-600$ & $0.991(8)$ & 30 & $20 \pm 16$ & $74 \pm 28$ & $76 \pm 10$ & $73 \pm 8$ & 35 & 18 & 23 & - & - \\
\hline 34 & Imidaclorpid-desnitro & $3-60$ & $0.994(3)$ & 3 & $131 \pm 108$ & $71 \pm 28$ & $89 \pm 12$ & $90 \pm 6$ & 20 & 14 & 20 & - & - \\
\hline 35 & $\begin{array}{l}\text { Isoproturon- } \\
\text { desmethyl }\end{array}$ & $6-120$ & $0.992(4)$ & 6 & $-22 \pm 14$ & $77 \pm 27$ & $87 \pm 9$ & $91 \pm 8$ & 31 & 20 & 23 & - & - \\
\hline 36 & $\begin{array}{l}\text { Me-Desphenyl- } \\
\text { Chloridazon }\end{array}$ & $30-600$ & $0.995(3)$ & 30 & $-20 \pm 12$ & $77 \pm 21$ & $83 \pm 6$ & $91 \pm 5$ & 18 & 19 & 21 & - & - \\
\hline 37 & Metazachlor ESA & $30-600$ & $0.99(7)$ & 30 & $11 \pm 10$ & $73 \pm 23$ & $68 \pm 8$ & $71 \pm 15$ & 62 & 21 & 22 & - & - \\
\hline 38 & Metazachlor OXA & $30-600$ & $0.993(2)$ & 120 & $35 \pm 35$ & $77 \pm 35$ & $62 \pm 12$ & $77 \pm 10$ & 33 & 22 & 28 & - & - \\
\hline 39 & Metolachlor ESA & $30-600$ & $0.989(8)$ & 30 & $14 \pm 9$ & $85 \pm 36$ & $88 \pm 17$ & $70 \pm 12$ & 20 & 13 & 19 & - & - \\
\hline 40 & Metolachlor OXA & $30-600$ & $0.993(5)$ & 60 & $30 \pm 15$ & $59 \pm 15$ & $97 \pm 11$ & $76 \pm 7$ & 29 & 13 & 20 & - & - \\
\hline 41 & Trichloropyridinol & $60-1200$ & $0.991(4)$ & 480 & $-7 \pm 10$ & $\begin{array}{c}108 \pm \\
30\end{array}$ & $80 \pm 11$ & $82 \pm 12$ & 31 & 22 & 21 & - & - \\
\hline
\end{tabular}

$\mathbf{n}^{\circ}$ : identification of molecules in Fig. 2 and Fig. 3, Domain: range of tested concentrations (ng. $\mathrm{g}^{-1}$ dw), dw: dry weight, LOQ: estimated limit of quantification (ng. ${ }^{-1}$ dw),

ME: matrix effect (\%), ER: extraction rate (\%), QF: quantification frequency, C2 to C6: tested concentration levels. 
Table 2. Pesticide residues quantified in fish and macroinvertebrates in $n g . \mathrm{g}^{-1} \mathrm{dw}$

\begin{tabular}{|c|c|c|c|c|c|c|}
\hline \multirow{2}{*}{ Molecule } & \multicolumn{3}{|c|}{ Fish $(n=17)$} & \multicolumn{3}{|c|}{ Macroinvertebrates $(n=19)$} \\
\hline & $\mathrm{QF}(\%)$ & Min - Max & Average \pm SEM & $\mathrm{QF}(\%)$ & Min - Max & Average \pm SEM \\
\hline Benzamide & 100 & $42-237$ & $116 \pm 12$ & 100 & $62-438$ & $174 \pm 23$ \\
\hline Imidacloprid-desnitro & 5 & 3 & - & 42 & $2-6$ & $3 \pm 1$ \\
\hline Fipronil & 0 & - & - & 5 & 4 & - \\
\hline Imidacloprid & 0 & - & - & 16 & $12-37$ & $21 \pm 8$ \\
\hline Prosulfocarb & 86 & $30-165$ & $67 \pm 8$ & 100 & $15-29$ & $21 \pm 1$ \\
\hline Tebuconazole & 0 & - & - & 11 & $3-8$ & - \\
\hline Terbutryn & 5 & 61 & - & 0 & - & - \\
\hline
\end{tabular}

QF: quantification frequency, dw: dry weight, Min - Max: minimal and maximal values quantified, SEM: standard error of the mean. 